\title{
Safer Spaces of Decolonize/Occupy Oakland: Some Reflections on Mental Health and Anti-Oppression Work in Revolutionary Times.
}

\author{
Erica Newman \\ Decolonize / Occupy Oakland
}

\begin{abstract}
Since its inception in October, the eruption of the Decolonize/Occupy ${ }^{1}$ movement in Oakland, California has been swift and powerful. Safer Spaces ${ }^{2}$ is a volunteer-run committee that was formed at the inception of Decolonize/Occupy Oakland to provide anti-oppression advocacy and mental and emotional wellness support to participants of the movement. We were created quickly, creatively, and with little lived experience of a movement this powerful to draw on for guidance. This is an overview of the work we have been doing, and a brief reflection on my experiences of our collective as we have worked to serve the movement.
\end{abstract}

Keywords: activist mental health, occupy Oakland

\section{Who We Are}

Safer Spaces $^{3}$ is a volunteer-run committee that has been working since the inception of Decolonize/Occupy Oakland to provide anti-oppression advocacy and mental and emotional wellness support to participants of the movement. We began in the days just before the encampment as a small meeting called by two friends to discuss how we, as Queer and Queer allied people, could contribute to the environment of the upcoming encampment as a Safe

\footnotetext{
${ }^{1}$ In solidarity with the struggles of Indigenous peoples, and in recognition of this history of this land, Safer Spaces uses the Decolonize/Occupy title for the Oakland movement. This title is also used frequently by the Decolonize/Occupy Oakland movement at large.

2 The term "Safer Space" originated in Women's and Queer movements of the past decades as an identifier of space that is explicitly committed to safety for individuals or communities that are targets of oppression. The identifier implies that the space takes an explicit anti-oppression stance, and will address oppressive behaviors directly.
} 
Space for us to participate. Over the past seven weeks our composition has shifted and grown as capacity, participant need, and environment have dictated. Currently, Safer Spaces is a committee of roughly 100 psychologists, social workers, counselors, and anti-oppression advocates. We organize through a combination of online correspondence, weekly meetings, and working groups designed to address major areas of need for the local movement, based on an agreed-upon set of values, and an openness to a vision that transforms organically with the movement and the growing composition of our committee.

\section{Values Framework}

It was immediately clear that for those of us at that initial meeting, our willingness to participate in the Occupy Movement was contingent on our safety as Queer and Queer allied people. For us, a sense of safety required that the movement take a clear anti-oppression stance, and be committed, in action, to the empowerment of all people. We have taken as our position that in order for collective liberation to occur, the emotional, mental, and somatic consequences of oppressive actions, such as harassment, exclusion, threats of physical violence, or other attacks on an individual's or group's integrity, must be recognized, held, and addressed. It is our goal to help serve this function for the Decolonize/Occupy movement by facilitating healing, advocacy, and accountability processes on interpersonal, collective, and systemic levels. This includes addressing psychological harm on these multiple levels. For example, we are working to address the traumatic use of violence by police with emergency and on-going socially just informed therapy, collective interventions that help to frame and work-through the effects of trauma in the movement, and by participating in larger wellestablished efforts against police brutality and the use of trauma by the State to repress dissent and disempower the general population, a.k.a. the $99 \%$.

Furthermore, it was, and still is, our stance that in order for any social movement to achieve the change we want to see in the world it must take the well-being of its participants seriously, and work with fierce integrity to address expressions of oppression within the movement itself. Simultaneously, we understand interpersonal violence as largely an expression of internalized oppressive beliefs and behaviors trained into us by a long history of white supremacist patriarchal capitalism. Therefore, for Safer Spaces of Decolonize/Occupy Oakland, we move forward with the basic assumptions that, 1) involvement in a social movement for collective liberation is understood as a necessary intervention towards individual well-being; 2) well-being and empowerment for all people is a necessary goal for any liberatory social movement; and 3) in order for any liberatory social movement to succeed, the well-being of its participants must be taken seriously. ${ }^{4}$

\section{What We Have Been Doing}

Decolonize/Occupy Oakland began with the occupation of a public plaza in front of Oakland City Hall. From the first day, Safer Spaces worked among ourselves, and among the encampment

\footnotetext{
${ }^{4}$ Our analysis has been heavily informed by the many formal and informal anti-oppression movements that have come before us. We are deeply in debt to the many organizing strategies that have been passed down to us by communities of color, and other groups marginalized under capitalism, patriarchy, and white supremacy. For an excellent resource on these many influences, see Chen, C., Dulani, J., \& Piepzna-Samarasinha, L. (Eds.). (2011). The Revolution Starts at Home: Confronting Intimate Violence in Activist Communities. Brooklyn, NY: South End Press.
} 
through literature and conversation, to make explicit the interconnections between mental health, safety, and oppression, and to identify ourselves as a source of support. We were a small group of people from various backgrounds and experiences who believed that politically informed mental health care was necessary for the camp, and who felt committed to it being there. For the first two weeks we met daily, and worked in shifts to provide 24-hour availability. We made announcements at the nightly General Assembly and introduced ourselves to others volunteering towards the camps infrastructure. Those of us who had worked to begin the committee had our hearts warmed as people came to volunteer in numbers we had not expected. Those first two weeks were a chaotic, exhausting, and brilliant time. There seemed to be an endless amount of work to be done to be able to carry out what we envisioned. As the camp developed, it became even clearer that what we had to offer was desperately needed, and yet the rate and intensity of camp life felt faster than our ability to intervene.

When the camp was raided on October 25 , hearts and bodies were broken. The violence done that night by the police destroyed the camp, injured campers, and led to the arrest of nearly 80 people. As a committee we expected trauma responses and immediately gathered to discuss how to intervene. Those of us who met chose to attend the rally that evening in protest of the raid and to assess the needs as we went. That night, when the police used tear gas and flashbang grenades, I watched as most people ran, as they should have, in fear. Those of us who had committed to staying for the wounded in times of violence witnessed who was left behind, and how the police responded with violence to the people coming to their aid. Two Safer Spaces volunteers were there to help the street medic team carry Iraq War veteran Scott Olson out of police fire. I remember, as I carried his body, thinking to myself, "How are we ever going to fix this?" "How will we be able to keep them from breaking us down?"

And so it has gone. Since that night there have been more occupation encampments, more police violence, and more for us to address and help heal as a movement. Since the repeated dispersals of the occupation camps by the city, we have adjusted by meeting weekly at locations offered to us by local allied organizations. Although this is working for us as a shortterm strategy, we struggle to offer services, and to be available as a resource to be called on without an established "home". Currently, resourcing to acquire a donated space is a major task of the group.

Considering the constant upheaval, passionate emotions, complex dynamics, and demanding work this stage of the movement necessitates, volunteer support has been a constant priority. In response to this, we are attempting to address sustainability by adopting a working group model for our current organizational structure. With this model, participants can gather at times that work for their schedule to organize the services they are most passionate about, and only need a delegate to attend the weekly meeting for report back, brainstorming, and accountability. Our current projects include:

- An Emotional Medic collective, modeled in part from street medic projects, to serve the emergency emotional needs of movement participants during social actions, after release from incarceration, or at occupation encampments.

- A referral service, whereby movement participants can be referred to local socially-just therapists, or other allied services, for longer term pro-bono, or low-fee services. 
- An anti-oppression advocacy collective that spearheads coalition, ally work, and accountability processes with participants struggling against oppression within the movement.

- Two "core-issue" working groups that facilitate interventions for Trauma, and Extreme States of Consciousness, i.e. psychosis, and other severe internal states.

\section{Reflections \& Moving Forward}

The structure laid out in the previous section is, quite honestly, the latest evolution of a constantly evolving strategy. As the physical location, movement strategies, and demographics of Decolonize/Occupy Oakland shift, the structure of our work must also constantly adapt. The values and visions that guide this occupation's Safer Spaces are intended to ground our work as we transition over time. Overall, it is our intent to build a broad community where we will work together to address oppression, violence, trauma, and mental health issues within this movement towards the goal its sustainability and success. Based on our experience so far, we expect that this will continue to require great flexibility, willingness to hold difficult and complex dynamics, and a serious commitment by a well-connected service community to working on ourselves, the groups we are a part of, and the physical space we are in. We are holding ourselves accountable to a goal of creating and maintaining an organizational structure and culture that makes it so that people from communities who are more impacted by state violence feel empowered to transition into more core positions. Those of us who are less impacted by state violence are stepping back as this happens. This is a beautiful and important process that provides us with grounding as we work to address our group's structure and sustainability.

I have frequently heard it said by Safer Spaces volunteers that the work of our committee and the Occupy Movement has given them the venue to act on their core values in a way that was previously unavailable to them. I believe that sentiment addresses both the newness of this territory, and the passion it allows people to embody and transmit. Perhaps this tension is what allows for continued action in the face of such enormous obstacles. This is a time when the challenge of creating a new society for this country is met with a set of skills and a sense of empowerment necessary for achievement. As psychologists, counselors, activists, and community members in service, how we show up for this task is a question that I hope will bring us into ever deeper conversations about the multiple locations where psychological wellbeing and social action intersect.

\section{Contact information/Correspondence:}

Erica Newman

psychrights@gmail.com

Erica Newman is a doctoral student of clinical psychology at The Wright Institute, Berkeley, California. Her study interests include the role of trauma in systems of oppression, and the locations where psychology and social action intersect. 